\title{
Value-in-Use and Mobile Technologies
}

\section{A General Approach for Value-in-Use Measurement and a Specific Application Based on Smartphone Usage}

With the increasing number of usage-based offerings, such as smartphone apps, consumers' usage processes are becoming increasingly relevant for scientific research. Thus, the concept of value-in-use is of particular importance. The paper presents a method for analyzing usage processes and capturing value-in-use. Based on a study of smartphone usage, the approach developed shows that valid value dimensions can be identified which characterize value-in-use. The proposed method proves to be a promising approach for value-in-use conceptualization.

DOI 10.1007/s12599-014-0349-x

\section{The Authors \\ Dipl. Kffr. Katherina Bruns ( $\varangle$ ) \\ Prof. Dr. Frank Jacob \\ Lehrstuhl für Marketing \\ ESCP Europe Wirtschaftshochschule \\ Berlin \\ Heubnerweg 8-10 \\ 14059 Berlin \\ Germany \\ kbruns@escpeurope.eu \\ fjacob@escpeurope.eu \\ url: http://www.escpeurope.eu/de/ \\ campus/berlin/}

Received: 2013-04-27

Accepted: 2014-04-09

Accepted after two revisions by Prof. Dr. Spann.

Published online: 2014-10-24

This article is also available in German in print and via http://www. wirtschaftsinformatik.de: Bruns K, Jacob F (2014) Value-in-Use und mobile Technologien. Ein allgemeiner Ansatz zur Messung des Value-inUse und eine spezifische Anwendung am Beispiel der SmartphoneNutzung. WIRTSCHAFTSINFORMATIK. doi: 10.1007/s11576-014-0437-z.

(C) Springer Fachmedien Wiesbaden 2014

\section{Introduction}

Service offerings that support people's daily lives including various processes and everyday situations are becoming increasingly widespread. Technological innovations are particularly common in this area (e.g., Ambient intelligence technologies, ISTAG 1999; Mobile computing, Müller-Veerse 1999; Ubiquitous computing, Weiser 1991). For example, mobile applications (apps) on smartphones can help to improve people's daily routines, such as driving to work or making appointments. A theoretical approach that addresses this development is the service-dominant logic ( $\mathrm{S}-\mathrm{D}$ logic, Vargo and Lusch 2004). Its central idea is that it is not tangible goods per se but rather their use that lays the foundation for economic exchange and contributes to value creation - e.g., a more efficient route guidance by using a navigation app. With the increasing recognition of this perspective, the concept of value-in-use (ViU) is becoming more important for understanding customers ${ }^{1}$ needs. Accordingly, value for the customer does not result from the exchange of goods (point of sale) in terms of valuein-exchange $(\mathrm{ViE})$ but rather from the usage process of an offering (point of use, $^{2}$ Weiber et al. 2011, p. 114). Thus, value creation becomes an ongoing process, which emphasizes customers' experiences as well as their ability to ex- tract value from the usage of products and other resources (ViU) (Grönroos and Voima 2013, p. 135). Consequently, we raise the following central questions: How can customers' usage processes be analyzed? How can the resulting value be captured? By which aspects can this value be described?

Although the growing relevance of $\mathrm{ViU}$ in relation to ViE can be illustrated by several examples in practice (e.g., mobile apps, music-streaming services, car sharing), it is still in an early stage in scientific research (Ostrom et al. 2010, p. 26). There has been an increase in empirical studies based on the theoretical assumptions of the S-D logic (e.g., Barrutia and Gilsanz 2013; Lemke et al. 2011; Moeller et al. 2013). However, the majority of articles is theoretical. Mainly conceptual studies discuss central aspects of the S-D logic, such as the constitution and integration of resources (e.g., Arnould et al. 2006; Kleinaltenkamp et al. 2012), the understanding of the role of value (e.g., Ng and Smith 2012; Woodruff and Flint 2006), and the processes of value (co)creation (e.g., Grönroos 2008; Rihova et al. 2013).

Despite the vast number of articles no concrete method exists for capturing usage processes and conceptualizing $\mathrm{ViU}$ which could be considered as universally valid. According to Grönroos and Voima (2013, p. 142), ViU is created by the customer. The provider plays a passive role,

\footnotetext{
${ }^{1}$ To facilitate reading, we make no distinction between female and male terms. Subsequently, we use the male pronoun.

${ }^{2}$ We are aware that the term "point of use" does not perfectly reflect usage processes and that process/period of use would be the more correct choice. However, for the terminological comparison with "point of sale," we follow the notation in Weiber et al. (2011, p. 114).
} 
as the customer only interacts with resources obtained from the provider, such as during the usage of a tablet PC. In this case, value emerges, for example, from the fact that customers are satisfying their need for information or possibly impressing their friends and colleagues. Heinonen et al. (2010) even refer to a "customer-dominant logic" which places further emphasis on the active role of the customer in the process of $\mathrm{ViU}$ creation. In line with this notion, Grönroos and Voima (2013, p. 147) and Heinonen et al. (2010, p. 545) call for new methods to analyze $\mathrm{ViU}$.

The present paper answers this call by proposing a method to analyze $\mathrm{ViU}$ and empirically testing this method in the specific context of smartphone usage. To this end, we apply Kelly's (1955) repertory grid method (RGM), which helps to capture the structure and content of subjective, complex perceptions. We make the following four contributions:

1. By further developing the RGM, we create an approach for analyzing usage processes.

2. When applying the method to the context of smartphone usage, we capture the resultant value for the customer in terms of value dimensions, which allow for the content-based specification of $\mathrm{ViU}$.

3. On the basis of the qualitative results, we translate the identified value dimensions into specific indicators.

4. In a quantitative study, we empirically test and validate the findings derived from the application of the adapted RGM and the resultant ViU scale.

After reviewing the theoretical background, we present the RGM in general and discuss the method's adaptation for the purposes of this study. The following empirical part of the paper is divided into two studies: The "Qualitative Application of the Adapted Method" section presents an example of the method's execution in the context of smartphone usage. Additionally, we identify relevant value dimensions in this context to develop content-related aspects of the $\mathrm{ViU}$ concept. In the "Quantitative Validation" section, we develop a measuring instrument to validate the findings from the qualitative study by means of a largescale survey. The article concludes with a critical discussion of the results and recommendations for further research.

\section{Theoretical Background}

\subsection{Service-Dominant Logic and Value-in-Use}

Over the past decade, there has been a shift of attention in marketing from goods-centered to service-centered approaches focusing on reciprocal relationships between the firm and the customer in terms of S-D logic (Vargo and Lusch 2004). According to this logic, service is a process and, as such, distinguished from a goods-dominant logic, which considers goods and services an outcome. A central component of such a process is not the exchange of tangible goods but rather the exchange of specialized competences in the form of knowledge and skills. For example, mobile devices, such as smartphones or tablet PCs, offer the possibility to keep in contact with other people or manage important documents. Therefore, the meaning of physical goods does not lie so much in owning them, as in using the service they provide - in this case, the ability to keep in contact or manage documents. For this service to be delivered, customers must learn how to use the offerings according to their needs (Vargo and Lusch 2004, pp. 9-11). Thus, customers are not passive participants in the usage process but are actively involved in the value creation process by integrating their knowledge and skills (Vargo and Lusch 2004, p. 11). Consequently, service is acquired by using an offering, which can lead to value for the customer, the so-called ViU.

This notion of value has challenged the prevailing $\mathrm{ViE}$ view. In contrast to the ViU concept, ViE describes value that is embedded in goods and determined by the producer (Vargo and Lusch 2004, p. 7). Goods and services are produced by the provider and are exchanged for money (monetary exchange value). Although $\mathrm{ViU}$ is more difficult to observe and measure than ViE, it is a more important concept both theoretically and managerially (Grönroos 2008, p. 304). Theoretically, $\mathrm{ViE}$ only exists if $\mathrm{ViU}$ can be created. For example, if customers do not expect to derive any use from a good, there will be no ViE for them. From the customer point of view ViE thus indirectly reflects expected ViU. In the long run, low or no ViU means low or no ViE (Grönroos 2008, pp. 303-304).

\subsection{Conceptualization of Value}

According to the S-D logic, value refers to the meaning a customer attaches to a product in a specific usage situation (Woodruff and Flint 2006, p. 185). Vargo and Lusch (2004, p. 9) view products as the distribution mechanism for services or the provision of satisfaction for higher-order needs (e.g., self-fulfillment, esteem). Their assumption is based on the means-end theory (Gutman 1982) which is used to understand value within value research (e.g., Woodruff 1997). According to this theory, customers prefer offerings that help them reach desirable goals. In the means-end approach, a broad view is taken on the value concept. The foundation for this is provided by Kelly's (1955) personal construct theory. Kelly argues that individuals perceive and evaluate the world (e.g., other people, events, things) on the basis of similaritydissimilarity dimensions, so-called "personal constructs" (Fransella and Bannister 1977 , p. 5). On the basis of such an evaluation, the customer adopts a way of thinking that is related to superior needs (Gutman 1982, p. 66). This relation is explained by the theory of construct implications (Hinkle 1965). In an extension of the personal construct theory, Hinkle (1965, p. 12) illustrates that the more superordinate personal constructs are, the more meaningful they are and the more likely they are to resist change, as opposed to constructs functioning at a lower level. Such superordinate constructs hence represent needs, based on which individuals construe their personal world.

With means-end theory and personal construct theory, a link between offerings (means) and underlying needs (ends) is established. However, it remains unexplored which needs precisely exist. Value research offers different value models that analyze customer needs on a more concrete level. Several approaches can be found that attempt to holistically conceptualize value (for a literature review, see Sanchez-Fernandez and IniestaBonillo 2007). Both one-dimensional (e.g., Zeithaml 1988) and multidimensional (e.g., Sheth et al. 1991; Sweeney and Soutar 2001) value models exist. According to Zeithaml (1988, p. 14), onedimensional approaches view value as the customer's overall assessment of the utility of a product based on the perception of what is received and what is given by the customer. While these onedimensional models refer to a trade-off 


Value Dimensions
Economic Value (efficiency and excellence,
functional value, price and performance,
extrinsic and systemic value)
Social Value (status and esteem)

Hedonic Value (play and aesthetics, emotional value, intrinsic value)

Altruistic Value (ethics and spirituality)

Epistemic Value

Conditional Value
Description

Relates to the fulfillment of a functional, utilitarian, or physical purpose. Focusses on rational, cognitive, and task-related aspects.

Refers to an image that is congruent with the norms of the customer's social environment as well as with the image the customer wants to represent externally.

Is related to different affective states, positive as well as negative. Includes aspects such as experience and entertainment.

Pertains to the passive appreciation of others. Encompasses virtuous and moral aspects.

Refers to the desire for knowledge, motivated by intellectual curiosity or novelty seeking.

Is related to the contingency of a market choice on the context/specific situation.
Sources

Hartman (1967); Holbrook (1996); Sheth et al. (1991); Sweeney and Soutar (2001)

Holbrook (1996); Sheth et al. (1991); Sweeney and Soutar (2001)

Hartman (1967); Holbrook (1996); Sheth et al. (1991); Sweeney and Soutar (2001)

Holbrook (1996)

Sheth et al. (1991)

Sheth et al. (1991) between benefits and sacrifices, multidimensional models conceptualize value as a set of dimensions that offer a holistic presentation of a complex phenomenon (Sanchez-Fernandez and Iniesta-Bonillo 2007 , p. 431). Based on the preceding discussion on value within the S-D logic, the present article adopts an understanding of value as a multidimensional model. In contrast to one-dimensional approaches, multidimensional models are not based merely on the cognitive and economic assessment of the utility of a product but also consider behavioral components (Sanchez-Fernandez and Iniesta-Bonillo 2007, p. 442).

There are different research streams pertaining to multidimensional value models. The main research streams can be summarized as follows. The theory of consumption value (Sheth et al. 1991) is based on the assumptions that (1) a customer's market choice is a function of multiple value dimensions, (2) these dimensions make different contributions depending on the choice situation, and (3) the dimensions are independent (Sheth et al. 1991, pp. 159160). Sheth et al. (1991, p. 160) differentiate "functional", "social", "emotional", "epistemic", and "conditional" value. Several studies build on this established theory. For example, Sweeney and Soutar (2001) use the dimensions to develop the PERVAL model (perceived value model). With the components "emotional", "social", and "functional" (price and performance) value, the authors generalize the original operationalization of the dimensions introduced by Sheth et al. (1991) (Sweeney and Soutar 2001, p. 208). Other studies have adapted Sheth et al.'s model (1991) to various study contexts in an attempt to create a more general scale for consumption value (e.g., Pura 2005; Wang et al. 2004).

Another research stream is based on Holbrook's (1996) value typology. Compared with the theory of consumption value, this typology rather focuses on experience-based value creation by considering values that become prominent during the consumption experience. The four global value types of "economic" (efficiency and excellence), "social" (status and esteem), "hedonic" (play and aesthetics), and "altruistic" (ethics and spirituality) value cover the majority of the dimensions present in other value models (Table 1). Holbrook's (1996) approach is partly built on the research activities regarding axiology theory (Hartman 1967), which differentiates "extrinsic", "intrinsic", and "systemic" value. Table 1 summarizes the value dimensions of each research stream on the basis of their common content.

When considering the conceptualization of value based on multidimensional models it becomes evident that the process-related dimension - the foundation of $\mathrm{ViU}$ - is often neglected. There is no clear distinction between the points in time of the value assessment (point of sale vs. point of use). Unlike the other value models, Holbrook's
(1996) value typology considers a usage situation. However, the complexity of the value dimensions hampers the operationalization of certain components (Sanchez-Fernandez and Iniesta-Bonillo 2007, p. 442). Thus, it remains unclear whether the dimensions of the discussed approaches are also suitable for the consideration of usage. In addition, the value dimensions of the models were mainly developed by the researchers themselves, and value was considered primarily in relation to a specific object or to characteristics of an offering, rendering the customer only a passive evaluator. In the S-D logic, however, customers are not passive recipients of value but rather active participants of value creation. Here, customers are not conceptualized as coproducers participating in the development of products and services, such as in the new generation of smartphones. Rather, value is created by the customers' integration of offerings into their personal processes, e.g., by using the smartphone to achieve certain goals ( $\mathrm{Ng}$ and Smith 2012, pp. 224-225). With regard to our research questions, the multidimensional understanding of value is therefore transferred to customers' usage processes. It is assumed that the needs evolving within these processes are crucial to customers' value assessment. For the empirical investigation in the present study, we use a methodology to capture $\mathrm{ViU}$ that is able to overcome the identified limitations of previous value models. 

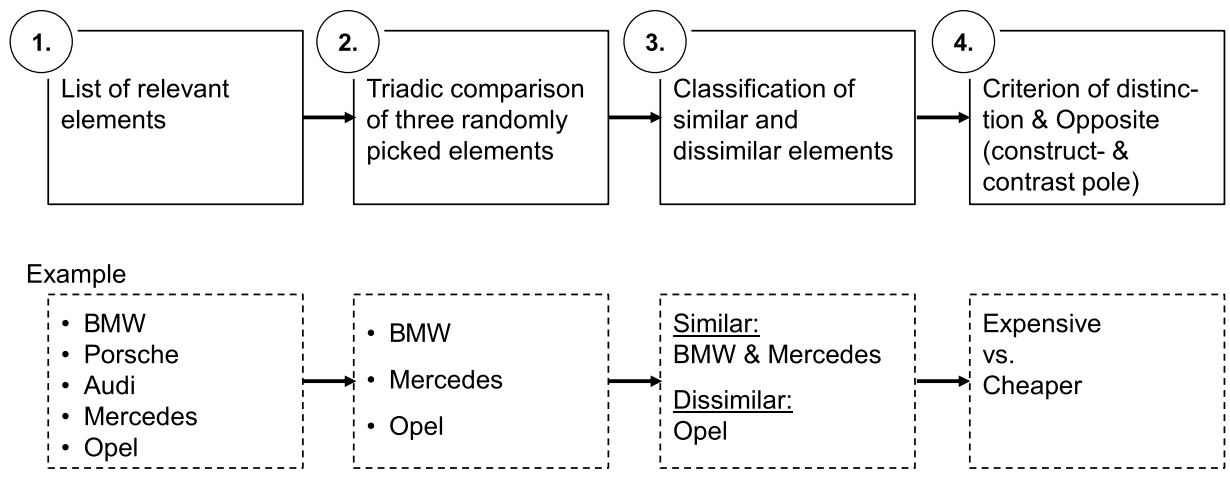

Fig. 1 The RGM procedure

\section{Development of a Methodology for Capturing Value-in-Use}

\subsection{Method Selection}

To adequately conceptualize ViU, we examined several research methods in terms of their applicability to our underlying questions. An appropriate methodology should first be able to reveal customers' processes. Second, it should identify the needs that are relevant to customers during the usage process. Due to its affinity to customers and their experiences during the interaction with offerings, certain insights can be expected from extant user research. Thus, we examined methods from this field in greater detail. User research provides a consistent, rapid, controlled, and thorough approach to investigating the user perspective (Goodman et al. 2012, p. 36). One area of user research comprises techniques such eye-tracking, log file analysis, task analyses as well as diary-studies. These methods all focus primarily on observations and provide information on users' activities or on how and when products and services are being used. Often a central objective of these studies is the implementation of specific features rather than discovering userspecific needs. For example, the target under investigation are typically specific characteristics of offerings, such as the speed or color of a website (e.g., Fang et al. 2012; Lee and Chen 2011). A second area of user research methods applies certain scales to operationalize users' experiences (e.g., Laugwitz et al. 2008). Methods in both areas are suitable for analyzing models, testing hypotheses, or developing segmentation. However, they fall short when a model's components and hypotheses need to be identified, as is the case in the present article. Another disadvantage of the first area of user research for our context is the focus on implementing single features. Consequently, we do not draw on either of the two described areas of user research in our subsequent investigation.

Focus groups and individual interviews such as qualitative in-depth interviews represent a third area of user research methods. These methods facilitate the identification of more complex behavioral patterns, such as customers' emotions or needs (Kuß and Eisend 2010, p. 132; Morgen and Krueger 1993, p. 17). Because ViU is a relatively new phenomenon, an exploratory approach with regard to these methods is most appropriate for our research objective. However, there are three substantial disadvantages of both focus groups and in-depth interviews. First, both methods are prone to biases caused by the group moderator, other participants, or the interviewer during execution. Second, the results of focus groups and in-depth interviews can be distorted by the subjective influence of the researcher on the interpretation of usage behavior (Corbin and Strauss 2008, p. 303; Goodman et al. 2012, p. 60; Morgan 1996, p. 140). A third disadvantage of these two methods is related to the complexity of the findings that inhibit a comparison between them (Kuß and Eisend 2010, p. 133).

To overcome the disadvantages of the discussed methods, the RGM (Kelly 1955) is most suitable. The RGM represents a concrete implementation of the personal construct theory mentioned previously and has already been applied in the area of user research (e.g., Hassenzahl and Wessler 2000). After providing a detailed description of this method's procedure, we discuss the applicability of the method to our central research questions. Figure 1 illustrates the individual steps of the procedure.
Kelly (1955) developed the RGM for analyzing an individual's personal construct system (Fransella and Bannister 1977, p. 5). As a first step, elements are collected for a given area of investigation (e.g., the automobile market). The elements comprise, for example, different people, events, and objects, for which personal constructs need to be identified. These elements (e.g., automobile brands) are either predefined or are determined by the respondent. As a second step, three randomly drawn elements (e.g., BMW, Mercedes, Opel) are presented to the respondent. As a third step, personal constructs are identified through a triadic comparison of these elements. Respondents are asked to distinguish two similar elements from a third, dissimilar element. As a fourth step, the criterion of differentiation is identified, and this defines the construct. In this indirect way, respondents can reveal constructs that they may not have been aware of prior to the interview. According to the technique of the triadic comparison, each evoked construct is bipolar. The similarity between two elements is termed the "construct pole", and the opposite of this pole is termed the "contrast pole" (e.g., "expensive" for BMW and Mercedes vs. "cheaper" for Opel). The second through fourth steps are repeated until no new constructs can be identified (Jankowicz 2004, p. 280). The personal constructs can then be used for further investigation (e.g., Bauer and Huber 2008, p. 967). Furthermore, by means of the so-called laddering method (Bannister and Mair 1968) superordinate constructs can be determined (Reynolds and Gutman 1984, pp. 158-159). This approach represents the methodological realization of the theory of construct implications (Hinkle 1965), which is, as we 
demonstrated previously, a further development of the personal construct theory and the theoretical link with the meansend theory. In this approach, respondents are asked to describe the reason for the relevance of an identified construct in more detail.

Compared to the other discussed methods, the RGM is a suitable choice with regard to our underlying research questions. The method offers both an exploratory research design and a structured procedure based on clearly defined steps. This standardized procedure allows for a comparison of results. Furthermore, the indirect questioning technique facilitates the depiction of unconscious dimensions and provides a window into respondents' subjective realities. Moreover, the questioning technique ensures that constructs are developed by the respondents themselves, which largely eliminates the potential for interviewer bias. In this way, the identified personal constructs represent aspects that are of the highest relevance to the test participants in terms of their language and content. Consequently, with the RGM, the three main disadvantages of focus groups and in-depth interviews are eliminated. Another significant argument for using the RGM is the aforementioned theoretical and methodological relationship to the means-end theory which is of importance for understanding value (e.g., Woodruff 1997, p. 142).

\subsection{Adaptation of the Repertory Grid Method}

The RGM has been applied to several research areas, such as consumer research in marketing (e.g., Heine 2009) and to user research (e.g., Hassenzahl and Wessler 2000). In both cases, different products or services are respectively used as elements for the triadic comparison technique. However, this to some extent conflicts with the present theoretical basis as well as with our central research questions, which focus on customers' usage processes as the basis of investigation. The methodological approach of the RGM, however, has numerous advantages over the other discussed methods. To adequately conceptualize ViU, we therefore propose an adaptation of the method (Table 2). For our purposes, the basis of investigation is no longer formed by object-related elements; instead, and in accordance with $\mathrm{ViU}$, process-related

Table 2 RGM: classical vs. adapted approach

\begin{tabular}{lll}
\hline & Classical, Object-Related RGM & Adapted, Process-Related RGM \\
\hline Theoretical foundation & Goods-dominant logic & S-D logic \\
Research objective & ViE & ViU \\
Input (elements) & Objects & Usage processes \\
Output (constructs) & Product attributes & Value aspects \\
\hline
\end{tabular}

elements are taken as a basis, i.e., customers' usage processes. To account for this key difference, we also adapt the second step of the RGM. In the triadic comparison, these process-related elements are therefore differentiated from one another with regard to usage and perceived value. The identified constructs represent aspects that become relevant to the user during usage and thus contribute to the constitution of ViU. The process-related adaptation allows for a methodological implementation of the fundamental assumptions of the S-D logic. With the shift from objects to usage processes, there is also a shift from provider to customer. According to Grönroos and Voima (2013, p. 141), value is created by the customer within the so-called "customer sphere", in which the provider can be engaged. By applying the adapted RGM - referred to as "pRGM" (= process-related RGM) in the following - the subsequent analysis shows how, in terms of the personal construct theory, customers construe value during their usage processes.

\section{Empirical Analysis}

\subsection{Smartphones as a Research Context}

We selected smartphones as the research context for the empirical analysis. Smartphones are mobile devices that are characterized by a vast number of computer-based features, including, for example, Internet access, locationbased services (e.g., check-in to locations with Swarm), and the opportunity to download and use third-party apps (Daurer et al. 2012, n. p.). Compared with laptops or tablet PCs, smartphones show a higher mobility (Yun et al. 2012, p. 123). Mobility is to be understood here as portability. Because of its size and weight the smartphone is easier to permanently carry around than laptops and tablet PCs. This suggests diverse opportunities for usability and distribution. Such advantages are reflected in the sales figures of smartphones as opposed to tablet PCs or laptops (22 Mio. vs. 4 and 6 Mio. in 2012 (BITKOM 2013a, 2013b; gfu 2013)). Smartphones play an increasingly important role in the mobile phone market. In Germany, smartphones currently account for more than $95 \%$ of the mobile phone market (BITKOM 2013a). The proliferation of smartphones illustrates the strong demand for them and their importance in people's lives. This reflects the notion that smartphones support people's daily routines, such as driving to work (through navigation or mapping services) or communicating with other people (e.g., chatting, phoning). In this way, the smartphone is increasingly becoming integrated into people's everyday lives and can further support these routines. This characteristic makes the smartphone an appropriate research context in the present article. First, a variety of usage processes are covered; second, by using smartphones, customers are engaged in an active role. For example, by using their own knowledge and skills and regardless of the provider, customers can independently determine how to best use their smartphone (e.g., listen to music, use notes) in any given situation (e.g., playing sports, going shopping). In doing so, the users can pursue different goals, such as entertainment, more efficient organization of daily routines, and so on. In this way, value creation is not only an outcome of the provider's contribution but also, and arguably more importantly, an artifact of the customer's own engagement - that is, the customer creates value by pursuing and achieving certain desirable goals through the adequate integration of skills and knowledge into the usage process (Vargo and Lusch 2004, p. 11; Kleinaltenkamp 2013, pp. 4-5). Consequently, the smartphone can be viewed as a platform on the basis of which customers can benefit within various contexts. 


\subsection{Qualitative Application of the Adapted Method}

\subsubsection{Sample and Execution of the Qualitative Study}

The qualitative analysis is based on a sample of 20 smartphone users living in Germany. Prior studies have shown ageand gender-specific differences regarding usage behavior of technologies. Therefore, we chose participants with varying backgrounds (e.g., age, gender, occupation) to ensure a reasonable variance in the data. For example, compared to men and younger people, women and older people are more strongly influenced by subjective norms when using new technologies (Morris and Venkatesh 2000, p. 392; Venkatesh et al. 2000, p. 50). By considering these diverse perspectives within our sample, we can counteract the disadvantages of a classical convenience sample (e.g., poor-quality data, lack of intellectual credibility) (Marshall 1996, p. 523). Furthermore, we consider respondents' experience with the research context to ensure their basic competence as informants, thus increasing the quality of the data (Marshall 1996, p. 523). The literature does not provide any minimum threshold recommendations for experience duration. An average value of 24.5 months of smartphone usage, with the shortest duration being 2 months, indicates that all participants should possess sufficient competence. In addition, a self-assessment of the respondents on a five-point scale ( 1 = "I have no knowledge" and $5=$ "I have very good knowledge") served as an indicator of competence. No respondents reported having no knowledge, and approximately half the respondents had either good or very good knowledge $(M=3.7)$. In total, 9 male and 11 female participants were interviewed, and ages ranged from 23 to 62 years. The sample includes students, doctoral candidates, employees, and executives from different industries (information technology, engineering, education, marketing, human resources, and medical care). In order to adequately respond to the test persons, interviews were conducted personally (by phone or face-to-face). They lasted 45 minutes on average.

The interviews were executed according to the procedure of the classical RGM. First, elements were determined for the triadic comparison. Jankowicz (2004, p. 42) recommends identifying
5-12 elements. Because the conditions should be kept simple for testing the applicability of the pRGM, respondents were asked to name five smartphone processes each. For processes to be selected, they had to create a personal value in the respondent's life. Moreover, we pointed out that the focal interest of the study are general smartphone usage processes that support respondents' daily lives, rather than concrete apps. To remember processes as realistically as possible, the respondents were asked to take a look at their smartphone display. After determining the elements, three of these usage processes were randomly selected and presented to the respondents. Respondents were asked to compare the presented processes and classify them into two similar processes and one dissimilar process with regard to usage and perceived value. On the basis of this triadic comparison, the constructs (i.e., the important aspects of smartphone usage) were revealed - in the following referred to as "value aspects". If respondents had difficulty perceiving a clear value aspect, the laddering technique was applied. By means of this additional questioning (e.g., "Why and how do you conduct this process?", "Why is this activity important to you?"), all uncertainty with regard to the delineation of differences or similarities could be eliminated. To create the contrast poles, respondents were then asked to indicate what they believed to be the opposite of the value aspect they had just listed. Triadic comparisons continued until the respondents could identify no further value aspects.

\subsubsection{Data Analysis and Results of the Qualitative Study}

We analyzed the data in two main steps. According to Lemke et al. (2011, p. 852), in the first step value aspects that appeared in more than one interview were standardized. The transcriptions were examined by two researchers to identify such repetitions and define standardized value aspect names. For example, 17 respondents reported interactions with other people as a value aspect of smartphone usage by mentioning construct poles such as "usage with others" or "other people integrated" and contrast poles such as "usage alone" and "no other people integrated". These value aspects were allocated to the name "interaction with other people". This procedure enabled us to reduce the 139 value aspects originally elicited across the 20 interviews to 40 standardized value aspects.

In the second step, value aspects were categorized into smartphone value dimensions based on their common meaning. In line with Jankowicz (2004, pp. 155-163) and Lemke et al. (2011, p. 856), the 40 standardized value aspects were written on separate cards, including construct and contrast poles as well as an illustrative quotation from the data. These cards were categorized by the two authors of the present article, who had collected the data, as well as by a third independent researcher. Categories were inductively formed, named, and defined. By comparing the identified categories, we computed an intercoder reliability index of $58 \%$ showing the proportion of the consistently allocated value aspects to a category. Because intercoder reliability was moderate, the three researchers discussed the categorizations, unified the allocations, and presented the results to a fourth independent researcher in the form of a list of categories, including their definitions and the construct cards. This researcher allocated the cards to the categories. A total of 36 correct allocations resulted in an intercoder reliability index of $90 \%$, thus reaching the benchmark of $90 \%$ agreement (Jankowicz 2004, p. 161). As after the first categorization, we discussed again the allocated categories and adjusted them accordingly. The results of this categorization appear in Table 3. In all cases, categories consist of a combination of value aspects of both types of interviews (face-to-face and by phone).

The smartphone value dimensions show similarities with dimensions of existing value concepts. However, they also reveal new aspects that have not yet been discussed in value research. This is demonstrated in Table 4, in which the obtained findings are compared with the value dimensions of the established models discussed previously.

A comparison with existing value research shows that, apart from "altruistic value", the global values of Holbrook's (1996) value typology are also relevant in smartphone usage. Further intersections occurred with Sheth et al. (1991) "conditional", "functional", and "epistemic" values. "Epistemic value", which describes the need for knowledge, can be clearly assigned to the value dimension "need for information/knowledge 
Table 3 Value dimensions of the smartphone usage

\begin{tabular}{|c|c|}
\hline Value Dimensions (Categories) & Value Aspects (Standardized) \\
\hline $\begin{array}{l}\text { Convenience } \\
\text { The user appreciates a comfortable and carefree } \\
\text { usage as well as a convenient handling }\end{array}$ & $\begin{array}{l}\text { - Cognitive effort } \\
\text { - Duration and speed of usage } \\
\text { - Temporal effort } \\
\text { - Level of activity }\end{array}$ \\
\hline $\begin{array}{l}\text { Flexibility/independence } \\
\text { The user wants to be as unrestricted, flexible, and } \\
\text { independent of location, Internet, and other devices } \\
\text { as possible during usage }\end{array}$ & $\begin{array}{l}\text { - Unrestricted usage } \\
\text { - Network independence } \\
\text { - Internet independence } \\
\text { - Location independence } \\
\text { - GPS independence } \\
\text { - Network with other devices }\end{array}$ \\
\hline $\begin{array}{l}\text { Hedonic value } \\
\text { The user wants to have fun, enjoy entertainment, } \\
\text { and relax from stress }\end{array}$ & $\begin{array}{l}\text { - Entertainment } \\
\text { - Fun } \\
\text { - Receiving stimuli } \\
\text { - Relaxation } \\
\text { - Emotional usage }\end{array}$ \\
\hline $\begin{array}{l}\text { Need for information/knowledge enhancement } \\
\text { The user wants to be consistently informed, he or she } \\
\text { wants to enhance knowledge, be up to date, and } \\
\text { know what is happening around him or her }\end{array}$ & $\begin{array}{l}\text { - Need for information } \\
\text { - Creation of information } \\
\text { - Knowledge enhancement }\end{array}$ \\
\hline $\begin{array}{l}\text { Personal self-fulfillment } \\
\text { The user wants to unfold and pursue personal } \\
\text { interest and own hobbies }\end{array}$ & $\begin{array}{l}\text { - Expressing creativity } \\
\text { - Pursue personal interests } \\
\text { - Hold on to personal things } \\
\text { - Self-reference }\end{array}$ \\
\hline $\begin{array}{l}\text { Productivity } \\
\text { The user wants to better organize and arrange his or } \\
\text { her daily routines and pursues clear goals and plans }\end{array}$ & $\begin{array}{l}\text { - Decision support } \\
\text { - Keep important data } \\
\text { - Organizing/structuring } \\
\text { - Goal orientation/goal pursuing } \\
\text { - Functional usage } \\
\text { - Time management/to-dos }\end{array}$ \\
\hline $\begin{array}{l}\text { Professionalism/need for achievement } \\
\text { The user wants to act dutifully and strives for } \\
\text { achievement and professionalism by meeting his } \\
\text { obligations }\end{array}$ & $\begin{array}{l}\text { - Professional usage } \\
\text { - Meet obligations }\end{array}$ \\
\hline $\begin{array}{l}\text { Self-expression } \\
\text { The user wants to be perceived and seen by others; } \\
\text { the user wants to show others what he or she is like } \\
\text { and satisfy the need to communicate }\end{array}$ & $\begin{array}{l}\text { - To present oneself } \\
\text { - Communicate important information } \\
\text { - Express oneself } \\
\text { - Be present in public }\end{array}$ \\
\hline $\begin{array}{l}\text { Social value } \\
\text { The user appreciates interaction with social contacts; } \\
\text { the user wants to maintain relationships, keep in } \\
\text { contact with friends and family, and communicate } \\
\text { with them }\end{array}$ & $\begin{array}{l}\text { - Establish contact with others } \\
\text { - Social usage } \\
\text { - Exchange information with others } \\
\text { - Interact with other persons } \\
\text { - Keep in contact with others } \\
\text { - Be close to other people }\end{array}$ \\
\hline
\end{tabular}

enhancement". The other two dimensions, however, are only partially transferable. While "conditional value" relates to situational factors, such as location or time, the "flexibility/independence" dimension also considers usage without restriction to certain devices, technical requirements, or the like. In addition, "functional value" can depict only a part (functional usage) of the "productivity" dimension. This dimension also refers to new aspects, such as organizing or pursuing plans, and is more consistent with Holbrook's (1996) "efficiency" value dimension (eco-

In addition to these new aspects, there are also completely new dimensions. For example, "social value" can be distinguished from previous findings. While in the present study this dimension refers to interaction with other people, "social value" according to Holbrook (1996), Sheth et al. (1991), and Sweeney and Soutar (2001) relates to personal status or appreciation by others. These aspects are better represented by the dimension "self-expression", which delineates the public reputation of the user. Furnomic value). thermore, the "personal self-fulfillment" dimension does not appear in the extant value research. This dimension includes value aspects such as expressing creativity or pursuing personal interests. These aspects foster the self-fulfillment of smartphone users by enabling them to pursue hobbies. Furthermore memories, such as taking pictures and editing them or taking notes of special thoughts, contribute to the personal value. The "professionalism/need for achievement" dimension is also new. Obligations in users' lives are paramount in this dimension. By meeting obligations, users can maintain their professionalism, especially in their working life. They strive for achievement and professionalism and want to avoid discomfort resulting from a lack of punctuality or forgetting important business agreements. The new aspects and dimensions are characterized by their inherent closeness to the user, which contrasts with the focus on the importance of products in existing value studies. The findings show that on the one hand there are similarities with established value dimensions, but on the other hand that models which focus on assessing value before usage (Sheth et al. 1991; Sweeney and Soutar 2001) are too narrow and cannot be transferred to usage processes without limitations. Thus, the application of the pRGM can provide a reliable method to identify established, general value dimensions. Furthermore, our findings indicate that previous studies have neglected aspects relevant for usage or even complete dimensions and that they consequently are not sufficient for capturing ViU.

By aggregating the concrete value aspects to more abstract value dimensions, we can determine the dimensions of $\mathrm{ViU}$ in the context of smartphone usage, which in turn allows for the specification of the content of this concept. These dimensions provide the basis for the second empirical study of this paper. Our goal in this study is to validate the qualitative and exploratory findings by means of a quantitative and confirmatory study with an appropriate sample. Because the focus of this study is the validation of the method and not necessarily the substantial review of all value dimensions, the study focuses on the dimensions that were identified from the most frequently mentioned usage processes. Accordingly, the study is based on the 
Table 4 Summary of the results compared with previous value research

\begin{tabular}{|c|c|c|}
\hline Value Dimensions & Previous Research & Sources \\
\hline Convenience & Economic value (efficiency) & Holbrook (1996) \\
\hline Flexibility/independence & Conditional value & Sheth et al. (1991) \\
\hline Hedonic value & $\begin{array}{l}\text { Emotional value, hedonic } \\
\text { value (Play) }\end{array}$ & $\begin{array}{l}\text { Holbrook (1996); Sheth } \\
\text { et al. (1991); Sweeney and } \\
\text { Soutar (2001) }\end{array}$ \\
\hline $\begin{array}{l}\text { Need for information/ } \\
\text { knowledge enhancement }\end{array}$ & Epistemic value & Sheth et al. (1991) \\
\hline Personal self-fulfillment & - & \\
\hline Productivity & $\begin{array}{l}\text { Functional value, economic } \\
\text { value (efficiency) }\end{array}$ & $\begin{array}{l}\text { Holbrook (1996); Sheth } \\
\text { et al. (1991) }\end{array}$ \\
\hline $\begin{array}{l}\text { Professionalism/need for } \\
\text { achievement }\end{array}$ & - & \\
\hline Self-expression & Social value (status, esteem) & $\begin{array}{l}\text { Holbrook (1996); Sheth } \\
\text { et al. (1991); Sweeney and } \\
\text { Soutar (2001) }\end{array}$ \\
\hline Social value & - & \\
\hline
\end{tabular}

communication-related usage processes of chat, phone calls, SMS, and emails (39 of the 100 mentioned processes within the pRGM). In addition, we considered communicating through social networks, due to the great significance that other studies have identified for this process (e.g., eMarketer 2014). Consequently, the six value dimensions that form the basis of the empirical study are "convenience", "hedonic value", "social value", "productivity", "self-expression", and "need for information/knowledge enhancement".

\subsection{Quantitative Validation}

\subsubsection{Sample and Execution of the Quantitative Study}

In cooperation with a German mobile network operator, we gained access to 807 smartphone users to conduct an online survey of the usage of communication services with the smartphone. The survey was conducted during the period of December 2012-January 2013 in Germany. The age distribution ranged from 15 to 65 years. The sample contained $46 \%$ female and $54 \%$ male respondents. Most respondents stated intermediate school leaving certificates (32\%) as their highest education, followed by advanced school leaving certificates (22\%) and university degrees (21\%).

Respondents were presented with a ViU scale for evaluating the communication services. The scale consisted of the six aforementioned value dimensions, assessed on a Likert scale with two reflective items each. Each item was briefly described and was assessed by indicating agreement on a five-point scale $(1=$ "strongly disagree"; $5=$ "strongly agree"). The generation of the measurement scale items was based on an inductive-deductive approach. Both transcriptions of the qualitative data and the content of the discussed corresponding components of the general value concepts (e.g., Holbrook 1996; Sheth et al. 1991) served as a starting point for formulating the indicators. The deductive data were adapted to the particular context of the present study. Content validity is indicated by the consideration of existing dimensions as well as by a pretest (five written and 15 web-based tests) that confirmed the comprehensibility of all items, so we included all items in the main study.

\subsubsection{Data Analysis and Results of the Quantitative Study}

To validate the proposed multidimensionality of $\mathrm{ViU}$ in the context of smartphone usage, we examined the items as part of a confirmatory factor analAMOS. We chose the confirmatory approach because this allowed to test both the number of factors, which were logically and theoretically predefined, and the assignment of the empirical indicators. Furthermore, this approach allows the researcher to evaluate the measurement model more precisely (Hinkin 1995, p. 977). After indicating the communication services they use, respondents rated these on the ViU scale. The majority of respondents indicated ysis using the statistical software SPSS that they use more than one service. Thus, they randomly evaluated two of the specified communication services. The data set was therefore restructured in such a way that an analysis of all individual ratings was possible. The reason for this was that our interest lies in the validation of the value dimensions for the entire communication area rather than in the possible differences between single communication services. In addition, the evaluations of the communication services do not differ significantly from each other $\left(\chi^{2}=23.4, p>0.05\right)$. After restructuring the data set and excluding respondents due to invalid answers, we were able to include 1427 individual evaluations in the analysis.

The assessment of model fit, reliability, and convergent and discriminant validity was based on Hair et al.'s (2010) recommended thresholds. The confirmatory factor analysis with all 1427 individual ratings demonstrated a satisfactory fit to the data $\left(\chi^{2}=153\right.$, RMSEA $=0.045$, $\mathrm{RMR}=0.03, \mathrm{SRMR}=0.02 ; \mathrm{GFI}=0.98$, AGFI $=0.96$, CFI $=0.99$, NFI $=0.99$ ). Both the inferential statistical and descriptive quality criteria are met. In addition, all items show reasonably high factor loadings with their respective value dimension and meet the required minimum values for all reliability measures (indicator reliability $>0.4$, composite reliability $>0.7)$. Convergent validity was also supported. Composite reliabilities of all dimensions are higher than the average variance extracted (AVE) values, which were well above 0.5 in all cases. These values also indicate internal consistency of the model. Discriminant validity was only partially fulfilled. The AVE value of the value dimensions "social value", "productivity", and "need for information/knowledge enhancement" did not exceed the squared correlation with another variable (Fornell and Larcker 1981, pp. 45-46). This limited discriminant validity can be explained by the focus of this study on social relationships which are typically associated with communication. The items of these three value dimensions, which were originally identified in the analysis of smartphone usage in general, were formulated with regard to the context of communication (Table 5). 
Table 5 ViU operationalization for smartphone usage with a focus on communication

\begin{tabular}{|c|c|c|c|c|c|}
\hline Value Dimensions/Items & $\mathrm{FL}^{\mathrm{a}}$ & $\mathrm{IR}^{\mathrm{b}}$ & $\mathrm{CR}^{\mathrm{b}}$ & $\mathrm{AVE}^{\mathrm{b}}$ & $\mathrm{DV}^{\mathrm{c}}$ \\
\hline \multicolumn{6}{|l|}{ When I am using communication service $\mathrm{XY}, \ldots$} \\
\hline Convenience $^{\mathrm{d}}$ & & & 0.76 & 0.62 & 0.41 \\
\hline$\ldots$ I find it very easy & 0.80 & 0.64 & & & \\
\hline .... it involves very little effort for me & 0.77 & 0.59 & & & \\
\hline Hedonic value & & & 0.83 & 0.71 & 0.70 \\
\hline ... it is pure entertainment for me & 0.84 & 0.71 & & & \\
\hline$\ldots$ I have a lot of fun & 0.85 & 0.72 & & & \\
\hline Need for information/knowledge enhancement & & & 0.85 & 0.74 & 0.96 \\
\hline $\begin{array}{l}\ldots I \text { am always up to date on what is happening in } \\
\text { my personal life }\end{array}$ & 0.87 & 0.76 & & & \\
\hline $\begin{array}{l}\text {... I learn the most important information/news } \\
\text { about friends }\end{array}$ & 0.85 & 0.72 & & & \\
\hline Productivity & & & 0.81 & 0.69 & 0.96 \\
\hline ...I plan certain activities with friends/colleagues & 0.83 & 0.69 & & & \\
\hline $\begin{array}{l}\text {... I arrange my daily routines (e.g., appointments } \\
\text { with friends) }\end{array}$ & 0.83 & 0.69 & & & \\
\hline Self-expression & & & 0.88 & 0.78 & 0.61 \\
\hline ...I express myself & 0.87 & 0.76 & & & \\
\hline ... I show others what I am like & 0.90 & 0.81 & & & \\
\hline Social value & & & 0.80 & 0.67 & 0.86 \\
\hline $\begin{array}{l}\text {...I have more frequent contact with my friends } \\
\text { and family }\end{array}$ & 0.83 & 0.69 & & & \\
\hline ... I feel closer to my friends and family & 0.81 & 0.66 & & & \\
\hline
\end{tabular}

${ }^{\text {a }} \mathrm{FL}=$ Factor loading

${ }^{\mathrm{b}} \mathrm{IR}=$ Indicator reliability. $\mathrm{CR}=$ Composite reliability. AVE $=$ Average variance extracted

${ }^{c} \mathrm{DV}=$ Discriminant validity. Values in this column are the highest squared correlations of the value dimension with the other value dimensions. Discriminant validity is present if values in this column are lower than the AVE for the respective value dimension

d Likert scale for all value-dimensions: from $1=$ "strongly disagree" to $5=$ "strongly agree"

\section{Discussion of Empirical Results}

\subsection{Implications of the Analysis}

The increasing number of offerings that serve to support consumers' daily routines has also led to an intensified discussion in scientific research concerning consumers' usage processes and the resultant ViU (e.g., Grönroos and Voima 2013; Heinonen et al. 2010; Lemke et al. 2011; Macdonald et al. 2011; Vargo and Lusch 2004). However, so far no universally valid method exists to capture this concept. In an effort to close this gap, the present study extends previous research by proposing a method for capturing ViU. The suggested methodology contributes to the literature both theoretically and methodologically.

The theoretical contribution is characterized by the conceptualization of
ViU regarding the content that has been developed by applying the proposed method. Thus, in the context of smartphone usage, numerous aspects are identified that are important to users during their usage processes. An aggregation of these value aspects results in nine different value dimensions, which are partially consistent with existing value models but also include novel and particularly usage-specific components. These nine dimensions facilitate the specification of the content of $\mathrm{ViU}$ in the context of smartphone usage. We have analyzed the majority of these value dimensions using a quantitative survey in the context of smartphone usage. To operationalize the dimensions, we developed indicators based on the gained content. In addition to the proposed method, which is recommended for usage processes in general, the scale we developed here further contributes to the research context of smartphone usage in particular. Apart from the limited discriminant validity, the results of the large-scale survey demonstrate an overall satisfactory model fit to the data. We can conclude that the pRGM - our adaptation of the more conventional RGM - provides a promising method for analyzing usage processes and ViU.

This study also makes methodological contributions. We provide a detailed description of the method and its adaptation for the current context, including a presentation of relevant terms and a discussion of its overall purpose (Table 2). According to Offermann et al.'s (2010, p. 298) evaluation criteria, we have thus demonstrated the applicability of the proposed method. Compared to previous value models, we conceptualized value by focusing on customers' usage processes. Using such a starting point within the RGM, the assumptions of the S-D logic can also be methodologically implemented. In addition, the standardized procedure allows for both repeated execution and comparability of results. With the application of the method, a basis for quantitative studies is established in which obtained value dimensions and relationships with other variables can be tested and analyzed.

From a practical point of view, the pRGM provides the possibility that future offerings can be better aligned with customers' usage processes and directly used by them according to their needs. The increasing integration of technological developments in customers' everyday objects has opened up many opportunities for providers to create corresponding offerings tailored to customers' usage processes (Weiber et al. 2011, pp. 112113). In particular, ambient intelligence technologies aim to comprehensively support the customer from the background (Bick and Kummer 2010, p. 311) and thereby enable detailed insights and possibilities for the provider to engage more effectively with customers' usage processes (Weiber et al. 2011, p. 112113). In addition to the usage-based development of offerings, providers may also be able to adjust their positioning strategies more directly to customers by considering usage processes. For example, smartphone users could be classified by the identified value dimensions, and offerings could be positioned accordingly. For users looking to have fun (hedonic value) and to be close to friends 


\section{Abstract}

Katherina Bruns, Frank Jacob

\section{Value-in-Use and Mobile Technologies}

A General Approach for Value-in-Use

Measurement and a Specific Application Based on Smartphone Usage

The increasing number of offerings that support consumers' daily routines has led to a growing discussion in scientific research about consumers' usage processes. A theoretical foundation for this discussion is offered by the servicedominant logic of marketing. The central idea is that value creation for a consumer is not based on mere product ownership but rather evolves through the usage of various offerings in terms of value-in-use. However, there is no universally accepted method to capture usage processes and analyze them with regard to value-in-use. The article therefore suggests a method for capturing value-in-use. For this purpose the repertory grid method is applied which is further adapted according to the underlying theoretical assumptions and empirically tested in a qualitative study on smartphone usage. On the basis of the findings, a specific valuein-use scale is then developed. Finally, this scale is validated in a quantitative study. The results indicate that the adapted repertory grid method is a promising approach to capture usage processes and the value-in-use created through these processes.

Keywords: Service-dominant logic, Value-in-use, Usage processes, Repertory grid method, Smartphone usage (social value), the service of video calling on the smartphone could be positioned as an offering through which users can enjoy events with their friends regardless of where they are (e.g., watching the FIFA World Cup together). A ViU orientation can also lead to more effective communication. For example, the value dimension "personal self-fulfillment" could be communicated through videos or posters depicting users engaging in their hobbies (e.g., making music, taking pictures) while they are using special smartphone programs. The customer can relate to the usage behavior presented and will thus feel more directly addressed. Moreover, focusing on usage behavior enables a provider to link the pricing of apps, for example, to the development of ViU. A notable example is the Spotify musicstreaming service, which offers different pricing models depending on users' needs. For example, a user seeking "flexibility/independence" can listen to music not only while stationary but also independent of the location over his or her smartphone by paying an extra charge.

\subsection{Limitations and Opportunities for Further Research}

In addition to the numerous contributions of the current research, several limitations are worth noting. One limitation results from the specific context in which we analyzed the pRGM (i.e., smartphone usage). With regard to generalization, further studies are necessary. However, due to its structured and standardized approach, it is likely that the method is not only suitable for the investigation of smartphone usage but also for the analysis of other usage processes. This assumption is supported by the categorization of "value creation spheres" introduced by Grönroos and Voima (2013, pp. 141-142). Usage processes, as they result from every offering, are assigned to the "customer sphere". Thus, a unified methodological view is also required.

The data obtained from the qualitative study were further examined in the particular area of communication in the context of smartphone usage. Thus, the quantitative study is limited to dimensions relevant to communication processes and the developed ViU scale is subsequently validated with regard to a specific context. However, the increasing integration of smartphones into people's daily lives demonstrates the importance of this research context. Furthermore, according to the S-D logic, value is always contextual (Vargo and Lusch 2008, p. 7). Future studies could extend the survey to smartphone usage in general and thus consider all value dimensions. Adjusting the items according to the context of smartphone usage in general could possibly eliminate the limited discriminant validity of the "social value", "productivity", and "need for information/knowledge enhancement" dimensions.

In addition to usage processes, future studies could also consider resources that the customer integrates while using an offering. These so-called "operant resources" are an important element in the creation of ViU according to the S-D logic (Vargo and Lusch 2004, p. 7). In the current paper, we have accounted for these operant resources implicitly in terms of own skills and knowledge, but future studies could explicitly investigate these and other resources, such as social operant resources (relationships with friends and family) (Arnould et al. 2006, p. 98). In this way, for example, the relationship between the different levels of integration of social resources and the manifestation of value dimensions could be examined in general but also for smartphone usage in particular (e.g., Königstorfer 2008; Woratschek and Durchholz 2012). The exploratory approach in this paper primarily focuses on revealing value dimensions for capturing ViU. Using large-scale surveys, future studies could try to provide information on the importance of the individual dimensions. By prioritizing the dimensions on the basis of their relative importance in different usage processes, practical implications could be derived. In addition, quantitative studies building on findings of a corresponding pRGM could investigate relationships such as the influence of ViU on relational outcomes such as satisfaction, word of mouth, and repurchase behavior. The transfer to usage processes in other contexts could further be beneficial for a much broader generalization of the proposed pRGM.

\section{References}

Arnould E, Price L, Malshe A (2006) Toward a cultural resource-based theory of the customer. In: Lusch RF, Vargo SL (eds) The service-dominant logic of marketing. Dialog, debate, and directions. Sharpe, Armonk, pp 91-104

Bannister D, Mair JMM (1968) The evaluation of personal constructs. Academic Press, London 
Barrutia JM, Gilsanz A (2013) Electronic service quality and value: do consumer knowledge-related resources matter? J Serv Res 16(2):231-246

Bauer HH, Huber $F$ (2008) Nutzenorientierte Produktgestaltung. In: Herrmann A, Homburg C, Klarmann M (eds) Marktforschung, 2nd edn. Gabler, Wiesbaden, pp 955-982

Bick M, Kummer TF (2010) Ambient intelligence. Bus Inf Syst Eng 2(5):317-320

BITKOM (2013a) Bundesverband Informationswirtschaft, Telekommunikation und neue Medien e.V. (BITKOM): Smartphones sorgen für 96 Prozent des Handy-Umsatzes. http://www.bitkom.org/de/markt statistik/ 64086_75052.aspx. Accessed 2013-03-03

BITKOM (2013b) Bundesverband Informationswirtschaft Telekommunikation und neue Medien e.V. (BITKOM): TabletVerkäufe übertreffen Erwartungen. http:// www.bitkom.org/de/presse/8477 75153. aspx. Accessed 2013-03-10

Corbin JM, Strauss AL (2008) Basics of qualitative research: techniques and procedures for developing grounded theory. Sage, Thousand Oaks

Daurer S, Molitor D, Spann M (2012) Measuring individual search costs on the mobile internet. In: Proc 20th European conference on information systems (ECIS), Barcelona

eMarketer (2014) Top 10 beliebteste AppKategorien nach Nutzeranteil in Europa im März 2013, zitiert nach de.statista.com. http://de.statista.com/statistik/daten/ studie/200824/umfrage/beliebteste-appkategorien-von-smartphone-nutzern-ineuropa-nach-nutzeranteil/. Accessed 201403-09

Fang X, Hu PJH, Chau M, Hu HF, Yang Z, Sheng ORL (2012) A data-driven approach to measure web site navigability. J Manag Inf Syst 29(2):173-212

Fornell C, Larcker D (1981) Evaluating structural equation models with unobservable variables and measurement error. J Mark Res 18(1):39-50

Fransella F, Bannister D (1977) A manual for repertory grid technique. Wiley, Chichester

gfu (2013) Gesellschaft für Unterhaltungsund Kommunikationselektronik (gfu): Consumer Electronics Marktindex Deutschland (CEMIX) Januar 2012-Dezember 2012. Accessed 2013-03-10

Goodman E, Kuniavsky M, Moed A (2012) Observing the user experience. Elsevier, Amsterdam

Grönroos C (2008) Service logic revisited: who creates value? And who co-creates? Eur Bus Rev 20(4):298-314

Grönroos C, Voima P (2013) Critical service logic: making sense of value creation and co-creation. J Acad Mark Sci 41(2):133-150

Gutman J (1982) A means-end chain model based on consumer categorization processes. J Mark 46(2):60-72

Hair J, Black W, Babin B, Anderson R (2010) Multivariate data analysis, 7th edn Prentice-Hall, Upper Saddle River

Hartman RS (1967) The structure of value: foundations of a scientific axiology. Southern Illinois Press, Carbondale

Hassenzahl M, Wessler R (2000) Capturing design space from a user perspective: the repertory grid technique revisited. Int J Hum-Comput Interact 12(3):441-459

Heine K (2009) Using personal and online repertory grid methods for the development of a luxury brand personality. Electron J Bus. Res Methods 7(1):25-38

Heinonen K, Strandvik T, Mickelsson KJ, Edvardsson $B$, Sundström $E$, Andersson $P$
(2010) A customer-dominant logic of service. J Serv Manag 21(4):531-548

Hinkin T (1995) A review of scale development practices in the study of organizations. J Manag 21(5):967-988

Hinkle DN (1965) The change of personal constructs: from the viewpoint of a theory of construct implications. PhD Thesis, Ohio State University

Holbrook MB (1996) Customer value - a framework for analysis and research. Adv Consum Res 23:138-142

ISTAG (1999) Information Society Technologies Advisory Group (ISTAG): orientations for workprogramme 2000 and beyond. $\mathrm{ftp}: / / \mathrm{ftp}$.cordis.europa.eu/pub/ist/docs/ istag-99-final.pdf. Accessed 2012-04-11

Jankowicz D (2004) The easy guide to repertory grids. Wiley, Chichester

Kelly GA (1955) The psychology of personal constructs: volume one - a theory of personality. Routledge, London

Kleinaltenkamp M (2013) Nutzungsprozesse - Die vernachlässigte Seite der Wertschöpfung. In: Schmitz G (ed) Theorie und Praxis des Dienstleistungsmarketing. Gabler, Wiesbaden, pp 1-25

Kleinaltenkamp M, Brodie RJ, Frow P, Hughes T, Peters LD, Woratschek H (2012) Resource integration. Mark Theory 12(2):201-205

Königstorfer J (2008) Akzeptanz von technologischen Innovationen: Nutzungsentscheidungen von Konsumenten dargestellt am Beispiel von mobilen Internetdiensten. Dissertationsschrift. Gabler, Wiesbaden

Kuß A, Eisend M (2010) Marktforschung: Grundlagen der Datenerhebung und Datenanalyse. Gabler, Wiesbaden

Laugwitz B, Held T, Schrepp M (2008) Construction and evaluation of a user experience questionnaire. In: Holzinger A (ed) USAB 2008. LNCS, vol 5298. Springer, Heidelberg, pp 63-76

Lee Y, Chen ANK (2011) Usability design and psychological ownership of a virtual world. $J$ Manag Inf Syst 28(3):269-308

Lemke F, Clark M, Wilson H (2011) Customer experience quality: an exploration in business and consumer contexts using repertory grid technique. J Acad Mark Sci 39(6):846-869

Macdonald EK, Wilson $\mathrm{H}$, Martinez $\mathrm{V}$, Toossi A (2011) Assessing value-in-use: a conceptual framework and exploratory study. Ind Mark Manage 40(5):671-682

Marshall MN (1996) Sampling for qualitative research. Fam Pract 13(5):522-525

Moeller S, Ciuchita R, Mahr D, OdekerkenSchroder G, Fassnacht M (2013) Uncovering collaborative value creation patterns and establishing corresponding customer roles. J Serv Res 16(4):471-487

Morgan DL (1996) Focus groups. Annu Rev Sociol 22:129-152

Morgen DL, Krueger RA (1993) When to use focus groups and why. In: Morgen DL (ed) Successful focus groups. Advancing the state of the art. Sage, Thousand Oaks, pp 3-19

Morris MG, Venkatesh V (2000) Age differences in technology adoption decisions: implications for a changing work force. Pers Psychol 53(2):375-403

Müller-Veerse F (1999) Mobile commerce report. Durlacher Research, London

$\mathrm{Ng}$ ICL, Smith LA (2012) An integrative framework of value. Mark Res Rev 9:207-243

Offermann P, Blom S, Levina O, Bub U (2010) Proposal for components of method design theories - increasing the utility of method design artefacts. Bus Inf Syst Eng 2(5):295-304

Ostrom AL, Bitner MJ, Brown SW, Burkhard KA, Goul M, Smith-Daniels V, Demirkan $H$, Rabinovich E (2010) Moving forward and making a difference: research priorities for the science of service. J Serv Res 13(1):4-36

Pura M (2005) Linking perceived value and loyalty in location-based mobile services. Manag Serv Qual 15(5):509-538

Reynolds TJ, Gutman J (1984) Laddering: extending the repertory grid methodology to construct attribute-consequence-value hierarchies. In: Pitts RE, Woodside AG (eds) Personal values and consumer psychology, Lexington, pp 155-167

Rihova I, Buhalis D, Moital M, Gouthro MB (2013) Social layers of customer-tocustomer value co-creation. J Serv Manag 24(5):553-556

Sanchez-Fernandez $R$, Iniesta-Bonillo MA (2007) The concept of perceived value: a systematic review of the research. Mark Theory 7(4):427-451

Sheth JN, Newman B, Gross B (1991) Why we buy what we buy: a theory of consumption values. J Bus Res 22:159-170

Sweeney JC, Soutar GN (2001) Consumer perceived value: the development of a multiple item scale. J Retail 77(2):203-220

Vargo SL, Lusch RF (2004) Evolving to a new dominant logic for marketing. J Mark 68(1):1-17

Vargo SL, Lusch RF (2008) Service-dominant logic: continuing the evolution. J Acad Mark Sci 36(1):1-10

Venkatesh V, Morris M, Ackerman P (2000) A longitudinal field investigation of gender differences in individual technology adoption decision-making processes. Organ Behav Hum Decis Process 83(1):33-60

Wang $Y$, Lo HP, Chi R, Yang $Y$ (2004) An integrated framework for customer value and customer-relationship-management performance: a customer-based perspective from China. Manag Serv Qual 14(2/3):169-182

Weiber R, Hörstrup R, Mühlhaus D (2011) Akzeptanz anbieterseitiger Integration in die Alltagsprozesse der Konsumenten: Erste empirische Ergebnisse. In: Fandel G, Fliess S, Jacob F (eds) ZfB-Sonderheft, 5/2011, Kundenintegration 2.0, Wiesbaden, pp 111-145

Weiser M (1991) The computer of the twentyfirst century. Sci Am 265(30):66-75

Woodruff RB (1997) Customer value: the next source for competitive advantage. J Acad Mark Sci 25(2):139-153

Woodruff RB, Flint DJ (2006) Marketing's service-dominant logic and customer value. In: Lusch $R$, Vargo $L$ (eds) The service-dominant logic of marketing: dialog, debate, and directions. Sharpe, Armonk, pp 183-195

Woratschek H, Durchholz C (2012) Cocreation of value by other customers - evidence in sports. Wirtsch-wiss Diskussionspap 4:1-40

Yun $H$, Kettinger WJ, Lee CC (2012) A new open door: the smartphone's impact on work-to-life conflict, stress, and resistance. Int J Electron Commer 16(4):121-152

Zeithaml VA (1988) Consumer perceptions of price, quality, and value: a means-end model and synthesis of evidence. J Mark 52(3):2-22 